\title{
Developing Argumentation Strategies in Electronic Dialogs: Is Modeling Effective?
}

\section{Elisabeth Mayweg-Paus, Fabrizio Macagno \& Deanna Kuhn}

To cite this article: Elisabeth Mayweg-Paus, Fabrizio Macagno \& Deanna Kuhn (2015):

Developing Argumentation Strategies in Electronic Dialogs: Is Modeling Effective?, Discourse

Processes, DOI: 10.1080/0163853X.2015.1040323

To link to this article: http://dx.doi.org/10.1080/0163853X.2015.1040323

Accepted author version posted online: 29

Apr 2015.

Published online: 29 Apr 2015.

Submit your article to this journal $\sqsubset$

Џ Article views: 79

Q View related articles ๘

View Crossmark data ¿ 


\title{
Developing Argumentation Strategies in Electronic Dialogs: Is Modeling Effective?
}

\author{
Elisabeth Mayweg-Paus \\ Department of Psychology and Sport Studies \\ Westfälische Wilhelms-Universität Münster, Münster, Germany \\ Fabrizio Macagno \\ Faculdade de Ciências Sociais e Humanas \\ Universidade Nova de Lisboa, Portugal \\ Deanna Kuhn \\ Department of Human Development \\ Teachers College, Columbia University
}

\begin{abstract}
The study presented here examines how interacting with a more capable interlocutor influences use of argumentation strategies in electronic discourse. To address this question, 54 young adolescents participating in an intervention centered on electronic peer dialogs were randomly assigned to either an experimental or control condition. In both conditions, pairs who held the same position on a social issue engaged in a series of electronic dialogs with pairs who held an opposing position. In the experimental condition, in some dialogs, unbeknownst to them (because dialog took place electronically), the opponent was a more capable ("expert") adult. Dialogs in the control condition were only with peers. Argumentation strategies of the experimental group who argued with the "expert" showed immediate strategy improvements in their subsequent peer dialogs, improvement absent in the control group (Cohen's $d=1.12$ ). In particular, the experimental group showed greater use of counterargument in general
\end{abstract}

Correspondence concerning this article should be addressed to Elisabeth Mayweg-Paus, Department of Psychology and Sport Studies, Westfälische Wilhelms-Universität Münster, Institute of Psychology for Education, Fliednerstraße 21, 48149 Münster, Germany. E-mail: e.mayweg@unimuenster.de 
and advanced forms of counterargument (undermining) that challenges the deeper premises or reasoning on which an argument is based. Implications with respect to mechanisms of change in the development of argumentation skills are considered.

\section{INTRODUCTION}

Argumentative dialogs are dialogical interactions in which participants have the dual goals of seeking to support their own position and to weaken an opponent's position (Walton, 2006; van Eemeren \& Grootendorst, 2004). Engaging students in dialogs with peers has been shown to be an effective educational approach to developing individual argument skills (Felton, 2004; Garcia Mila, Gilabert, Erduran, \& Felton, 2013; Iordanou, 2010, 2013; Iordanou \& Constantinou, 2015; Kuhn \& Moore, 2015; Kuhn, Hemberger, \& Khait, 2014; Kuhn \& Udell, 2003; Kuhn \& Crowell, 2011; Nussbaum, 2008a, 2008b; Osborne, 2010; Osborne, Erduran, \& Simon, 2004). Dialogic argumentation strategies improve when students have the opportunity to engage in sustained exercise of these strategies in supportive environments (Crowell \& Kuhn, 2014; Reznitskaya et al., 2001). There remains much to learn, however, regarding the mechanisms by means of which such advances occur.

More is involved than the improvement of individual cognitive skills via practice. Argumentation is a social activity, and social factors accordingly are implicated in its development (Kuhn, 2015; van Eemeren \& Grootendorst, 1984, 1992, 2004; Walton \& Krabbe, 1995). But what, more precisely, is their role? One factor presumed to play a central role in the quality of communicative exchange and learning is the interlocutors' level of competence (for an overview of the field of computer-supported instructional communication see Deiglmayr et al., 2014). Constructivist theories claim that learning is particularly fostered if a learner interacts with a more capable partner who provides guidance and support. The difference in competencies challenges the partner and helps to reduce the distance between the actual and the potentially achievable developmental level, such as in Vygotsky's (1978) zone of proximal development. Research in the field of tutoring is consistent with this idea in pointing to the importance of constructive activities between interaction partners possessing different levels of skill (Chi, Siler, Jeong, Yamauchi, \& Haumann, 2001; Graesser, Person, \& Magliano, 1995). Participants in collaborative discussions have been observed to imitate one another's argument strategies (Anderson et al., 2001; Kim, Anderson, Kim, \& Archodidou, 2007). Furthermore, expert-peer interactions have the potential to prompt novices to reflect on their own reasoning through the use of specific questions, with a view to developing metacognitive skills (Erduran, 2007; Zohar, 2012; Zohar \& Ben David, 2008). Electronic dialogs in particular have this potential as 
they provide a written record of the exchange that serves as a reflection tool (Kuhn, Goh, Iordanou, \& Shaenfield, 2008; Kuhn et al., 2013).

\section{Assessing Argument Strategies}

Improving students' argument skills presupposes knowledge of the strategies that need improvement, that is, what counts as more sophisticated and effective dialogic behavior. A possible answer can be found in the literature on argumentation, which is a useful resource to determine what can count as ideal or more reasonable model of argumentative discussion (van Eemeren, \& Grootendorst, 1984, 1992, 2004; Walton, Reed, \& Macagno, 2008). In argumentation theory, dialogs have been analyzed by distinguishing their distinct types and the various levels at which an issue is debated and investigated (Krabbe, 2003; Walton \& Krabbe, 1995).

A fundamental role is played by different types of counterarguments and questioning, which can shift the dialog to a deeper level or to another connected issue. Counterarguments and rebuttals constitute the core of argument, because these are the core strategies used to weaken the interlocutor's argument and to support and defend one's own view. An arguer, for example, can advance an incompatible claim in an attempt to establish the unacceptability of the other's conclusion, or the arguer can undermine the opponent's argument broadly by asking critical questions (Walton et al., 2008).

Arguers engaged in dialogic argumentation with one another thus seek to accomplish their goals by means of multiple strategies. They may focus more on the opposition of incompatible positions (associated with more frequent use of the strategy of direct counterargument), or they may focus more on the search for an alternative and potentially mutually acceptable position (associated with more frequent use of arguments supporting an alternative conclusion), In the case of direct counterargument, an opponent's argument may be weakened by invoking contradictory evidence or by faulting the reasoning underlying the argument (identified here as undercutting). In all cases a goal is to avoid pseudoagreements or pseudo-disagreements (Jucks \& Paus, 2013; Naess, 1966; Paus \& Jucks, 2012) and focus the discussion on the true source of the difference in opinion (Aristotle, 1995). Use of these different argument strategies can shed light on the underlying structure of how an issue is debated and resolved. In particular, undercutting has been considered a particularly strong strategy given its capacity to address deeper grounds of disagreement, bringing to light background beliefs that may otherwise escape attention.

In this theoretical framework, we conducted the present study to investigate the hypothesis that interacting with an interlocutor who displays deeper and more effective argumentative moves (an expert) stands to benefit the development of more sophisticated argumentation strategies on the part of the novice interlocutor 
in electronic dialogs. In such dialogic interactions, participants face the need to contribute relevantly to the dialog by replying adequately to the moves made by the more skilled opponent. In this fashion, the need to adapt to the communicative behavior of the interlocutor and respond accordingly may lead the relative novice to adopt more sophisticated strategies and to increasingly use these strategies as the dialog continues (Alexander, 2006; Osborne et al., 2004), thereby expanding his or her argumentation skill repertoire. In the work presented here, we address the idea of enhancing argumentation skill through interactions with more skilled arguers by focusing on specific argumentation strategies in a dialogic framework. The interaction with an expert interlocutor who displays these specific, more sophisticated argumentative moves is assumed to guide the novice's potential argumentative moves by restricting the possible replies (Macagno, MaywegPaus, \& Kuhn, 2014; Macagno \& Walton, 2014; van Laar, 2014).

Participants were middle-school students partaking in a multiyear intervention using the method described by Kuhn and colleagues (Crowell \& Kuhn, 2014; Kuhn \& Crowell, 2011; Kuhn, Zillmer, Crowell, \& Zavala, 2013; Kuhn \& Moore, 2015) in which students engage in pairs in electronic dialogs with a succession of pairs of peers who hold an opposing view on a topic. Before and after six such twice-weekly dialog sessions, students work on same-side teams to prepare for a final whole class debate on the topic between the two teams. Details are presented in Methods. We chose the second and third of four topics addressed during the school year (whether misbehaving students should be expelled from school; whether the United States should come to the aid of a country being attacked by a neighbor) as the focus of our analysis. Thus, all participants had experience participating in argumentative dialogs with peers. Participating pairs of students, who shared a position on a topic and who remained partners throughout work on the topic, were randomly assigned to either an experimental or control condition. Their experience of engaging with pairs of peers who held an opposing view was identical except that in the case of experimental pairs, the opposing pair for three of their dialogs consisted not of peers but rather an adult "expert" (a Ph.D. student) who served as the conversational partner, unbeknownst to the student pair. (This was possible because the "pro" and "con" teams on the topic met in separate rooms to confine their communication to the electronic channel.)

\section{METHODS}

\section{Participants}

Fifty-four participants, 11 to 13 years old, were sixth to eighth grade students attending a public middle school in an ethnically diverse low- to lower-middle 
income neighborhood in New York City. Genders were equally represented in the school population and within conditions, as were demographic characteristics. Of the student body, approximately $20 \%$ were non-Hispanic whites, $30 \%$ African American, and 50\% Hispanic; 60\% qualified for free or reduced-price lunch. All students spoke English, but most Hispanic students came from homes where Spanish as well as English were spoken. They were all participants in an ongoing twice-weekly curriculum in argumentation (Kuhn et al., 2014) that the school had adopted as part of its regular curriculum. It focused on electronically conducted peer dialogs between pairs of students who held opposing positions on a social issue.

\section{Intervention Method}

Students participated in a twice-weekly 50-minute class across the entire school year. Our staff identified themselves to students as coaches rather than teachers, with one playing the role of lead coach and one or two others as assistants. ${ }^{1}$ The year was divided into four quarters of 13 class sessions each. A unique topic was introduced each quarter as the basis for that quarter's work. The two topics students addressed in the dialogs examined in the present study were whether misbehaving students should be expelled from school and whether the United States should come to the aid of a country being attacked by a neighbor. Students chose their sides on each topic. Topics had been pilot-tested to achieve an approximately equal number of students who favored each side.

Each topic cycle began with small-group team work ("Pregame") and proceeded to pair dialogs with the opposing side ("Game"). Final small-group preparation preceded a whole class "Showdown" debate that served as the capstone experience of the sequence ("End-game"), followed by a debrief session and final individual essay assignment. The role of adult coaches was largely organizational and directed toward facilitating group process (the only exception being the Debrief session, described below, when the lead coach assumed a more active role). (For further details regarding the method, see Kuhn et al., 2014.)

\section{Pregame (Sessions 1-3)}

Students met in same-side groups of 7 to 8 . Coaches circulated, encouraging participation; the coach did not introduce reasons or comment evaluatively on reasons generated by students. The first pregame session ("Our Reasons") was devoted to generating reasons why the position the group favored is the better one and assembling a set of "Reason cards" that represented their supporting reasons.

\footnotetext{
${ }^{1}$ We thank David Shaenfield for his role in data collection.
} 
At the second session ("Evaluating Reasons"), they reflected on and ranked Reason cards with respect to their strength.

\section{Game (Sessions 4-9)}

Students were paired with the same same-side peer throughout this phase. Together, they argued against a sequence of six opposing-side pairs, a different such pair each session. Dialogs of about 25 minutes took place electronically via Google chat software, facilitating reflection on what was said. While waiting for the opposing pair to respond, the same-side pair worked on a reflection sheet each session, referring to the ongoing dialog transcript that appeared on the screen before them. These were one of two forms (alternated across sessions): one asking the pair to identify and reflect on one of their own arguments and the other on one of the opponents' arguments. Each asked for identification of counters and rebuttals and whether these could be improved.

\section{End-Game (Sessions 10-13)}

Students returned to same-side small groups and engaged in two sessions of preparation for a final "Showdown" whole-class debate. One session focused on reviewing the other-side arguments encountered in the dialogs. The focus was on identifying the opponents' strongest arguments and determining the best counterarguments to use against them in the Showdown. The other session focused on reviewing own-side arguments, identifying expected counterarguments, and determining the best rebuttals to use against them.

At the Showdown session, one member at a time was decided on by the small group to come to a "Hot Seat" and verbally debate someone from the opposing side. Whenever they wished, those on either team could call a 1-minute huddle to confer.

In a debrief session, the lead coach guided students through an argument map, which was a transcription of the showdown. As homework, students were assigned to write individual essays justifying their final positions on the topic.

\section{Experimental Manipulation}

The present study addresses only a circumscribed part of the intervention, the Game phase comprising the dialogs themselves. Three of students' electronic dialogs on a single topic were chosen for investigation. Because students preferred working with same-gender peers as their same-side partners, we paired students of the same gender unless the gender ratio of the same-side team precluded doing so (fewer than $10 \%$ of pairings). Thus, pairs of mostly samegender students who held the same position on the topic had been formed at the outset of the activity as described above. For purposes of this study, 16 of the 
student pairs (equally drawn from the two sides of the topic) were randomly assigned to the experimental condition. The remaining 11 pairs (also equally drawn from the two sides) were in the control condition. Control pairs conducted all their dialogs with pairs of peers, as was the normal case during this intervention as described above. Of the 27 pairs, 13 discussed the topic of school expulsion (5 in the experimental group) and the remaining 14 discussed the issue of the United States providing aid to country being attacked by a neighbor (6 in the experimental group). These topics were chosen to cover the range topics used during the intervention.

The experience for students in the experimental condition was modified. Of the six dialogs students pairs engaged in on the topic, among students in the experimental condition for half of these (the second, fourth, and sixth) dialogs, an adult expert was substituted for an opposing peer pair, unbeknownst to participants because the dialogs were electronic. Experts were instructed to respond to students' contributions in ways that would be most effective in weakening them.

Students in the control condition engaged only in dialogs with peers; the fourth dialog thus consisted of a peer dialog for control pairs and an adult expert for experimental pairs. The focus of investigation became the third and fifth dialogs; these were chosen instead of the initial dialogs to ensure students were familiar with the topic and to thereby secure a more accurate indication of their argumentation skill. We chose this microanalytic technique to be able to attribute any change over time specifically to the expert's modeling of more sophisticated argumentation strategies.

\section{Coding of Argumentation Strategies}

The first step was to design a coding scheme aimed at detecting and classifying the types of argumentation strategies observed. Previous work (Crowell \& Kuhn, 2014) drew on Walton (2006) in developing a coding scheme that emphasized the proportion of the arguer's statements that were attempts to weaken the opposing side's position, either by directly criticizing it (Pollock, 1974, 1987) (Counter C) or by proposing an argument supporting an alternative and incompatible viewpoint (Counter A). Counter Cs can be regarded as attacks to the conclusion of an argument. The arguer challenges a viewpoint by advancing the reasons why it cannot be accepted. Counter As are not simple negations of a viewpoint but rather proposals of alternative arguments that leave the opponent's argument unaddressed. Counter Cs can thus be regarded as stronger than Counter As, but within the Counter $\mathrm{C}$ category strategies also differ. The arguer may attack the opponent's argument, for example, by pointing to the negative consequences of its conclusion (e.g., "he wouldn't have another school to go to if he was expelled"). Or the arguer may attack the reasoning itself by identifying 
conclusions that do not follow or by bringing to light and challenging often implicit premises on which the argument is based (e.g., "just because he's misbehaving doesn't mean he can't learn"). In the present work, the examination of the more sophisticated arguments of the experts led us to add this latter type of counterargument as a third category, which we call Underminer. Undermining an opponent's argument consists of either (1) attacking the inferential link between premises and conclusion or (2) rejecting one of the premises supporting the conclusion (Walton, 2005, 2006, 2007; Walton et al., 2008). The coding scheme is presented in Table 1.

As a first step in coding the dialogs, each contributor's utterances were divided into idea units because sometimes more than one idea unit was expressed in a turn (Asterhan \& Schwarz, 2009; Jucks \& Paus, 2013). Idea units were further divided into on-task units (i.e., addressed to the argumentation task) or off-task units (e.g., "it was fun to work with you") with a high inter-rater agreement of $\kappa=.94$ for roughly $50 \%$ of the dialogs (31 of 65 ). In a next step, two raters coded approximately one-third of the dialogs (22 of 65) to assign statements to a strategy type. The remaining idea units were assigned to the category "other." These included such types as requests for clarification, clarifications, interpretations of the opponent's statement, and additions to an opponent's statement without opposing it. Again, inter-rater agreement was high, with $\kappa=.91$. Differences were resolved by discussion, and one rater coded the remaining dialogs.

\section{RESULTS}

\section{Experts' Dialogs}

As a first step, the experts' argument strategies were analyzed. The argument strategies of the three experts were characterized by a very high proportion of ontask units $(91 \%)$ and, most important, by a high proportion use of Underminers $(55 \%)$. The three experts had slightly different styles, reflected in Underminer proportions of $67 \%, 58 \%$, and $46 \%$. Overall, most of the experts' other moves (25\%) consisted of the stronger type of the other two counterargument types identified above - the counter-critique (Counter C) - in which the opposing position is directly criticized with intention to weaken.

An illustration of an expert interacting with a peer pair is given in Table 2. The expert challenges the relevance of the students' practical reasoning (move 6), which leads the student pair to defend their position by attacking the value concerning the responsibility of the school toward the students (move 7). This attack on values is in turn challenged by the expert, who points out the higher responsibility of the school, that is, teaching students moral virtues (move 8). Moves 11 and 12 represent 


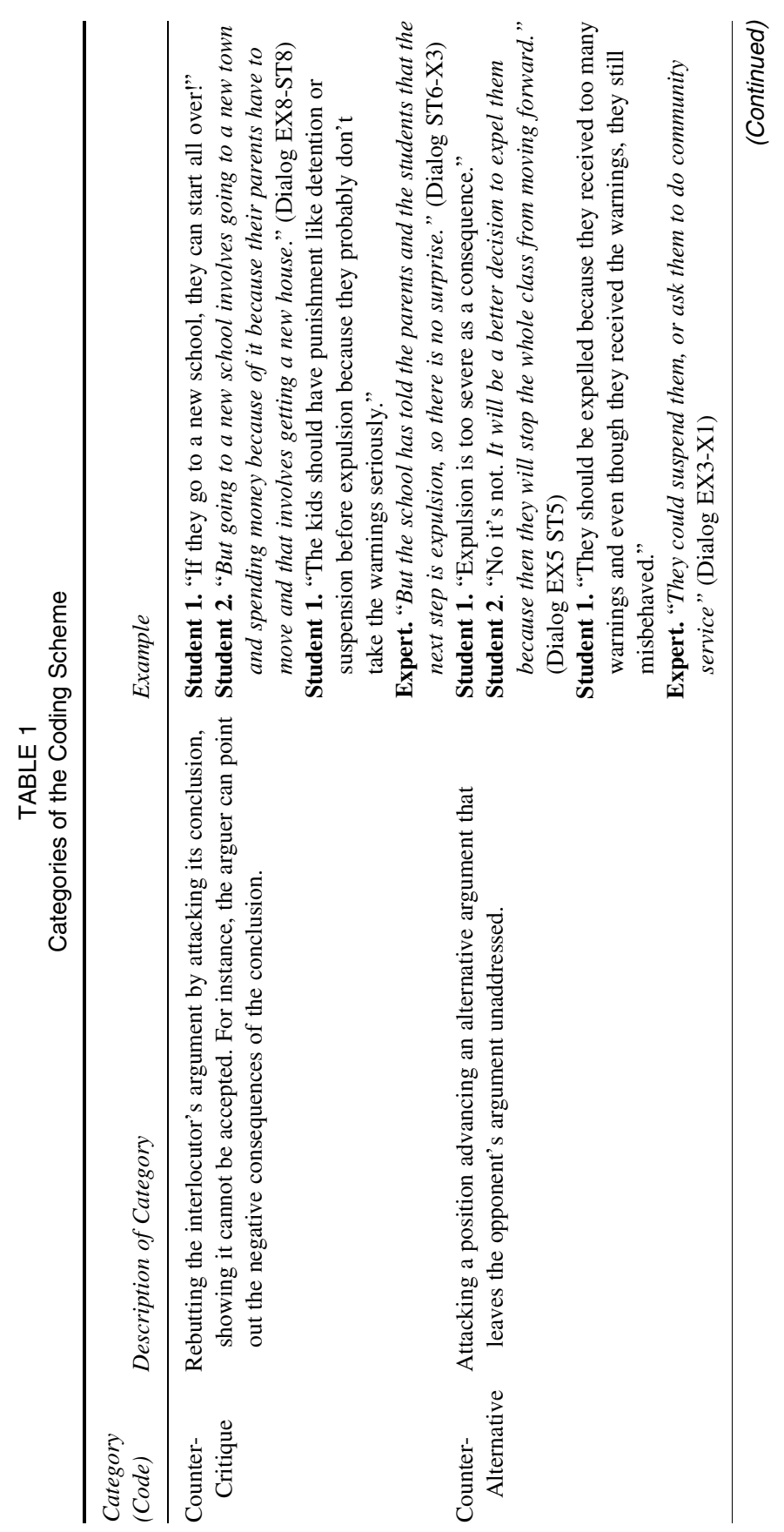


TABLE 2

Illustration of an Expert-Peer Dialog

\begin{tabular}{|c|c|c|c|}
\hline Turn & $\begin{array}{l}\text { Dialog } \\
\text { Partner }\end{array}$ & Contribution & $\operatorname{Code}^{a}$ \\
\hline 1 & EX4 & $\begin{array}{l}\text { We think Doris and Roger should be expelled because they are } \\
\text { not following the rules. }\end{array}$ & $\mathrm{O}$ \\
\hline 2 & Expert & $\begin{array}{l}\text { Yes, but they should be given more chances to improve by staying } \\
\text { in school. }\end{array}$ & $\mathrm{CC}$ \\
\hline 3 & EX4 & $\begin{array}{l}\text { They have had too many chances and their behavior still does } \\
\text { not improve. }\end{array}$ & $\mathrm{U}$ \\
\hline 4 & Expert & $\begin{array}{l}\text { The school can't give up on the kids. They need to have an education. } \\
\text { They should get counseling at school. }\end{array}$ & $\mathrm{CC}$ \\
\hline 5 & EX4 & Yes but they can move to a different school. & $\mathrm{CC}$ \\
\hline 6 & Expert & $\begin{array}{l}\text { But that just moves the problem to another school. If the kids don't } \\
\text { get help they will disrupt class in another place. }\end{array}$ & $\mathrm{U}$ \\
\hline \multirow[t]{2}{*}{7} & EX4 & $\begin{array}{l}\text { True, but they WANT to be expelled. Doris and Roger knew the } \\
\text { consequences. They knew if they kept doing that, they will get } \\
\text { expelled. But they kept doing that so they chose to expel themselves. }\end{array}$ & $\mathrm{O}$ \\
\hline & & & $\mathrm{U}$ \\
\hline \multirow[t]{3}{*}{8} & Expert & $\begin{array}{l}\text { The adults at the school will know what Doris and Roger need. } \\
\text { Perhaps they do want to expel themselves, but they need to learn } \\
\text { to be good and they can do that in school. }\end{array}$ & $\mathrm{U}$ \\
\hline & & & $\mathrm{O}$ \\
\hline & & & $\mathrm{CA}$ \\
\hline \multirow[t]{2}{*}{9} & EX4 & $\begin{array}{l}\text { Who's going to teach them to be good because all the teachers are } \\
\text { busy? They won't have the time. }\end{array}$ & $\mathrm{CC}$ \\
\hline & & & $\mathrm{O}$ \\
\hline \multirow[t]{2}{*}{10} & Expert & $\begin{array}{l}\text { They can get help from counselors too. Schools have that, but if } \\
\text { they get expelled who will help them? }\end{array}$ & $\mathrm{CA}$ \\
\hline & & & $\mathrm{U}$ \\
\hline \multirow[t]{2}{*}{11} & EX4 & $\begin{array}{l}\text { How do you know that there are counselors? Besides, their parents } \\
\text { can help them. }\end{array}$ & $\mathrm{U}$ \\
\hline & & & $\mathrm{CA}$ \\
\hline \multirow[t]{2}{*}{12} & Expert & $\begin{array}{l}\text { All schools have counselors or advisors that help students think } \\
\text { about their behavior. Their parents can help them regardless of } \\
\text { if they are in school or not. }\end{array}$ & $\mathrm{U}$ \\
\hline & & & $\mathrm{O}$ \\
\hline 13 & EX4 & $\begin{array}{l}\text { Their parents have been told about their behavior and their parents } \\
\text { have not done anything about it. }\end{array}$ & $\mathrm{CC}$ \\
\hline 14 & Expert & I agree. That's why the adults at the school should help them. & $\mathrm{O}$ \\
\hline
\end{tabular}

${ }^{\mathrm{a}}$ Abbreviations are $\mathrm{O}$, other; $\mathrm{CC}$, counter $\mathrm{C}$; CA, counter $\mathrm{A}$; U, Underminer.

another relevant exchange of deeper attacks. In response to a critical question about the existence of counselors, the expert provides the information and then undermines the relevance of the proposal made (move 12). 
TABLE 3

Proportion Use of Argument Categories by Group

\begin{tabular}{|c|c|c|c|c|}
\hline \multirow[b]{2}{*}{ Categories } & \multicolumn{2}{|c|}{ Expert Group } & \multicolumn{2}{|c|}{ No-Expert Group } \\
\hline & $\begin{array}{l}\text { Pair } 1 \\
M(S D)\end{array}$ & $\begin{array}{l}\text { Pair } 2 \\
M(S D)\end{array}$ & $\begin{array}{l}\text { Pair 1 } \\
M(S D)\end{array}$ & $\begin{array}{c}\text { Pair } 2 \\
M(S D)\end{array}$ \\
\hline Counters & $.42(.27)$ & $.27(.18)$ & $.55(.17)$ & $.52(.28)$ \\
\hline Underminers & $.22(.15)$ & $.46(.26)$ & $.16(.14)$ & $.21(.18)$ \\
\hline Others & $.35(.30)$ & $.29(.26)$ & $.29(.19)$ & $.27(.19)$ \\
\hline
\end{tabular}

\section{Students' Dialogs}

Across both conditions, dialogs between student pairs contained an average of 13.93 on-task idea units $(S D=5.53$; range, 7-28). Dialogs were of similar length, for example, the average did not significantly change from the initial $(M=14.52, S D=4.39)$ to the later student-student dialog $(M=13.56, S D$ $=7.63) ; F(1,25)=2.06, p=.16, n s$ (Figure 1$)$.

We next analyzed change of argumentation strategy use across dialogs by condition, examining first the mean proportion of Underminers (proportion to the total number of idea units used) contributed by each pair during each of the dialogs (see Table 3 for descriptives). Student pairs who had interacted with experts used a significantly greater proportion of Underminers in their subsequent dialogs, whereas student pairs who had not interacted with experts did not change

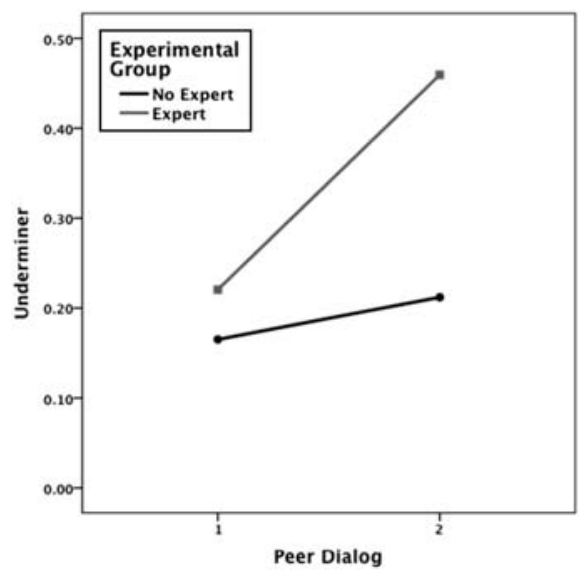

FIGURE 1 Percentage use of Underminer category by condition. 
their argumentation strategy (did not increase the proportion of Underminers used), interaction $F(1,25)=4.15, p=.05, \eta_{p}^{2}=.14$ (Figure 1). To specify this interaction, additional post-hoc tests were used. Student pairs in both groups used the same amount of Underminers in the initial dialogs before the experimental intervention, $t(27)=1.01, p=.32$, $n s$. However, student pairs who interacted with an expert used more Underminers in the subsequent peer dialog than student pairs who did not interact with an expert, $t(27)=-2.93, p=.01, d=1.12$. This effect was also confirmed within each of the experimental groups: Compared with the initial peer dialog, student pairs in the expert group used more Underminers in

TABLE 4

Example of a Peer-Peer Dialog After Expert Interaction

\begin{tabular}{|c|c|c|c|}
\hline Turn & $\begin{array}{l}\text { Dialog } \\
\text { Partner }\end{array}$ & Contribution & Code $e^{a}$ \\
\hline 1 & EX4 & $\begin{array}{l}\text { Doris and Roger should be expelled because if they stay in the } \\
\text { school other kids will follow them. }\end{array}$ & $\mathrm{O}$ \\
\hline 2 & ST2 & They still have a right to learn. & $\mathrm{CC}$ \\
\hline 3 & EX4 & They can be homeschooled with a tutor. & $\mathrm{CA}$ \\
\hline 4 & ST2 & Their parents might be too busy and not have enough money. & $\mathrm{U}$ \\
\hline 5 & EX4 & They can go to a different school. & $\mathrm{CA}$ \\
\hline 6 & ST2 & That's just moving the problem. & $\mathrm{U}$ \\
\hline 7 & EX4 & $\begin{array}{l}\text { But how is that moving the problem, it will help the other kids in } \\
\text { the school focus. }\end{array}$ & $\mathrm{U}$ \\
\hline 8 & ST2 & What about the other school they are going to? & $\mathrm{CC}$ \\
\hline 9 & EX4 & $\begin{array}{l}\text { If they can't move because that will move the problem, Columbia } \\
\text { town school might have tutors who can teach them during or } \\
\text { after school. }\end{array}$ & $\mathrm{CA}$ \\
\hline 10 & ST2 & What makes you think they will listen? & $\mathrm{CC}$ \\
\hline 11 & EX4 & If they can't listen then they should be expelled. & $\mathrm{CC}$ \\
\hline \multirow[t]{2}{*}{12} & ST2 & $\begin{array}{l}\text { It is not their fault that they have emotional problems but they have } \\
\text { to learn to get a good job and have a good life. The schools can't } \\
\text { just throw him out on the streets. }\end{array}$ & $\mathrm{U}$ \\
\hline & & & $\mathrm{CC}$ \\
\hline 13 & EX4 & $\begin{array}{l}\text { Why would the school throw them out on the streets all they are } \\
\text { telling them is that they need to go to a new school because } \\
\text { they keep disrupting the class and they can't follow the rules. }\end{array}$ & $\mathrm{U}+\mathrm{O}$ \\
\hline 14 & ST2 & $\begin{array}{l}\text { But sure enough they will get expelled from the new school. They } \\
\text { have to be treated. }\end{array}$ & $\mathrm{CC}$ \\
\hline 15 & EX4 & $\begin{array}{l}\text { They can be homeschooled if either their parents have the time or } \\
\text { they can get a homeschool teacher. }\end{array}$ & $\mathrm{CA}$ \\
\hline 16 & ST2 & But they won't listen to the tutor. & $\mathrm{CC}$ \\
\hline 17 & EX4 & $\begin{array}{l}\text { If they are not going to listen to anybody in or out the school what is } \\
\text { the point of having them learn? }\end{array}$ & $\mathrm{U}$ \\
\hline 18 & ST2 & They have to be counseled. & CA \\
\hline
\end{tabular}

a Abbreviations are $\mathrm{O}$, other; $\mathrm{CC}$, counter $\mathrm{C}$; CA, counter A; U, Underminer. 
the subsequent peer dialog, $t(11)=2.52, p=.02, d=1.15$, whereas there was no difference within the no-expert group, $t(16)=.84, p=.41, n s$.

In contrast, student pairs in both groups did not show any change in the mean proportion of other Counters (Counter-critique and Counter-alternative combined), $F(1,25)=1.56, p=.24, n s$. Hence, it appears only the Underminer category was affected by the dialog with experts.

An example illustrates the use of Underminers by students in the second peer pair interaction (Table 4). The peer-peer pair interaction that followed the dialog with the expert shows a strategy that differs from the one that appeared in the first peer-peer interaction. In the second, principles underlying the viewpoints are apparent, with possible internal contradictions identified. Underminers are used to attack the interlocutor's arguments at different levels. The second pair (ST2) first attacks the conditions of the practical reasoning claimed by the other pair, noting how the argument is based on a potentially unrealistic assumption (move 4). Then, they challenge the further alternatives advanced by questioning their relevance to the solution of the problem (move 6), which leads to a metadiscussion of the relevance of the move itself (move 7). The second pair then challenges the values underlying the first pair's proposal, bringing to light the deep commitments concerning the role of schools in a community. This challenge opens a dialog on a different level aimed at solving a possible misunderstanding (moves 12 and 13). Finally, the first pair undermines the interlocutor's attacks, showing how commitment to the children's inability to listen to anybody conflicts with another commitment to having them learn (move 17).

\section{DISCUSSION}

The present study demonstrates that interacting with an expert can have an immediate and direct effect on subsequent higher-order cognitive performance. Specifically, the behavior of an expert arguer in electronic dialogs positively influenced the immediate argumentative moves of a novice early adolescent pair and influenced their further moves, relative to a control group who argued only with peers. Among counterarguments, we distinguished more superficial counters from deeper-level ones (Underminers) that address underlying reasoning and/or grounds of disagreement. For pairs in the experimental condition, Underminers were not a frequent argumentative move at the first dialog but increased in frequency after the experience of arguing with a relative expert. Participants in the experimental condition thus modified their strategies in the direction of those modeled by the expert and then used such strategies in further dialogs to attack the interlocutor's arguments at a deeper level.

At a broad level, these results show that young adolescents accommodate their communicative and social behavior to the behavior of those with which they 
interact. When they are afforded the challenge to engage a more sophisticated strategy by observing its use by a conversational partner, they are frequently able to do so, even though these more advanced strategies were not explicitly taught. Thus, dialogic practice, when augmented with strategic modeling, may be a powerful combination. However, it remains an interesting question whether the results would have differed if participants had been aware they were engaged in discourse with an adult. Our results show only that it is not necessary to have such awareness for the effects of this experience to manifest themselves. One could speculate whether such awareness would even increase the orientation toward the partner (as an expert model), but an answer awaits future research. Beyond this, the study presented here was aimed at the identification of specific short-term effects. Future research should examine how far these effects extend to new contexts and/or topics, thereby indicating more global change in argumentation strategy use.

The present results thus point to a promising approach to fostering higherorder intellectual skill development in the classroom. In their dialogic approach to developing argument skills, Kuhn et al. (2014) emphasize the transfer from social to individual competence, stemming from a sociocultural tradition, as well as the fundamental role of dense engagement and practice over an extended period. The present findings suggest the possibility of integrating with this practice short interactions with a more accomplished interlocutor. Experiencing an interaction with a skilled interlocutor may be of help not only in skill development but also in leading students to interiorize the dialogic frame in argumentative writing, understanding better and appreciating the purpose of argumentation and the values associated with it (Kuhn, Wang, \& Li, 2011; Kuhn et al., 2013). Such "natural" learning approaches could be of considerable promise in addressing motivational issues, with students playing an active role in the developmental process, as sociocultural theories highlight.

The practical outcomes of this study are confined to a specific type of argumentative move, which defined the notion of expert, as well as to a particular type of population and a particular set of topics that participants addressed. Further work is needed to assess their generalizability to more natural contexts in which teachers, parents, and other adults potentially play the expert role examined here, addressing different topics and performing other types of moves. Nevertheless, broader implications of the development of this specific argumentation strategy can be highlighted. As pointed out by works in argumentation theory (Walton et al., 2008), undermining corresponds to the most effective critical questioning of an argument and presupposes the reconstruction of the grounds of an argument and the detection of the possible weak or unshared premises. The use of this strategy presupposes the use of metacognitive skills and results in a deep critical assessment of the interlocutor's arguments. Although the quality of argument production is not directly addressed by this study, 
sophisticated thinking skills are involved in the process of reconstructing, evaluating, and challenging the grounds of an argument. On this view, these results go beyond the learning of an argumentation strategy.

Another practical consideration is the duration of the effects observed in this study. Would they persist over a longer time period than that of the study period itself? Furthermore, because students worked in same-side pairs, the study design does not allow an analysis of the effects on each member of a student pair separately. These questions also require further research. In sum, the study presented here provides a promising foundation for extending the work in such directions.

\section{REFERENCES}

Alexander, R. J. (2006). Towards dialogic teaching: Rethinking classroom talk. Cambridge, UK: Dialogos.

Anderson, R. C., Nguyen-Jahiel, K., McNurlen, B., Archodidou, A., Kim, S., \& Reznitskaya, A. (2001). The snowball phenomenon: Spread of ways of talking and ways of thinking across groups of children. Cognition and Instruction, 19, 1-46.

Aristotle. (1995). Topics. In J. Barnes (Ed.), The works of Aristotle. Princeton, NJ: Princeton University Press.

Asterhan, C. S. C., \& Schwarz, B. B. (2009). Argumentation and explanation in conceptual change: Indications from protocol analyses of peer-to-peer dialog. Cognitive Science, 33, 374-400.

Chi, M. T. H., Siler, S., Jeong, H., Yamauchi, T., \& Hausmann, R. G. (2001). Learning from human tutoring. Cognitive Science, 25, 471-533.

Crowell, A., \& Kuhn, D. (2014). Developing dialogic argumentation skills: A three-year intervention study. Journal of Cognition and Development, 15, 1-46.

Deiglmayr, A., Paus, E., McCall, C., Mullins, D., Berthold, K., Wittwer, J., ... Rummel, N. (2013). Towards an integration of the learning perspective and the communication perspective in computersupported instructional communication. Journal of Media Psychology, 25, 180-189.

Erduran, S. (2007). Methodological foundations in the study of argumentation in science classrooms. In S. Erduran \& M. P. Jiménez-Aleixandre (Eds.), Argumentation in science education. Perspectives from classroom-based research (pp. 47-69). Dordrecht, Netherlands: Springer.

Felton, M. (2004). The development of discourse strategies in adolescent argumentation. Cognitive Development, 19, 35-52.

Garcia Mila, M., Gilabert, S., Erduran, S., \& Felton, M. (2013). The effect of argumentation task goal on the quality of discourse. Science Education, 97, 497-523.

Graesser, A. C., Person, N. K., \& Magliano, J. P. (1995). Collaborative dialogue patterns in naturalistic one-to-one tutoring. Applied Cognitive Psychology, 9, 495-522.

Iordanou, K. (2010). Developing argument skills across scientific and social domains. Journal of Cognition and Development, 11, 293-327.

Iordanou, K. (2013). Developing face-to-face argumentation skills: Does arguing on the computer help. Journal of Cognition and Development, 14, 292-320.

Iordanou, K., \& Constantinou, C. (2015). Supporting use of evidence in argumentation through practice in argumentation and reflection in the context of Socrates learning environment. Science Education, 99, 282-311. doi:10.1002/sce.21152

Jucks, R., \& Paus, E. (2013). Different words for the same concept: Learning collaboratively from multiple documents. Cognition and Instruction, 31, 1-28. 
Kim, I., Anderson, R. C., Kim, N. -J., \& Archodidou, A. (2007). Discourse patterns during children's collaborative online discussions. Journal of the Learning Sciences, 16, 333-370.

Krabbe, E. C. W. (2003). Metadialogues. In F. H. van Eemeren, J. A. Blair, C. A. Willard, \& A. F. Snoek Henkemans (Eds.), Anyone who has a view: Theoretical contributions to the study of argumentation (pp. 83-90). Dordrecht, Netherlands: Kluwer.

Kuhn, D. (2015). Thinking together and alone. Educational Researcher, 44, 46-53. doi:10.3102/ 0013189X15569530

Kuhn, D., \& Crowell, A. (2011). Dialogic argumentation as a vehicle for developing young adolescents' thinking. Psychological Science, 22, 545-552.

Kuhn, D., Goh, W., Iordanou, K., \& Shaenfield, D. (2008). Arguing on the computer: A microgenetic study of developing argumentation skills in a computer-supported environment. Child Development, 79, 1310-1328.

Kuhn, D., \& Udell, W. (2003). The development of argument skills. Child Development, 74, $1245-1260$.

Kuhn, D., Hemberger, L., \& Khait, V. (2014). Argue with me: Argument as a path to developing students' thinking and writing. Bronxville, New York: Wessex.

Kuhn, D., \& Moore, W. (2015). Argument as core curriculum. Learning: Research and practice, 1.

Kuhn, D., Wang, Y., \& Li, H. (2011). Why argue? Developing understanding of the purposes and value of argumentive discourse. Discourse Processes, 48, 26-49.

Kuhn, D., Zillmer, N., Crowell, A., \& Zavala, J. (2013). Developing norms of argumentation: Metacognitive, epistemological, and social dimensions of developing argumentive competence. Cognition \& Instruction, 31, 456-496.

Macagno, F., Mayweg-Paus, E., \& Kuhn, D. (2014). Argumentation theory in education studies: Coding and improving students' argumentative strategies. Topoi: An International Review of Philosophy. doi:10.1007/s11245-014-9271-6

Macagno, F., \& Walton, D. (2014). Emotive language in argumentation. New York, NY: Cambridge University Press.

Naess, A. (1966). Communication and argument. London, UK: Allen \& Unwin.

Nussbaum, E. M. (2008a). Using argumentation vee diagrams (AVDs) for promoting argument/ counterargument integration in reflective writing. Journal of Educational Psychology, 100, $549-565$.

Nussbaum, E. M. (2008b). Collaborative discourse, argumentation, and learning: Preface and literature review. Contemporary Educational Psychology, 33, 345-359.

Osborne, J. (2010). Arguing to learn in science: the role of collaborative, critical discourse. Science, $328,463-466$.

Osborne, J., Erduran, S., \& Simon, S. (2004). Enhancing the quality of argumentation in school science. Journal of Research in Science Teaching, 41, 994-1020.

Paus, E., \& Jucks, R. (2012). Common ground? How the encoding of specialist vocabulary impacts on peer-to-peer online discourse. Discourse Processes, 49, 565-598.

Pollock, J. L. (1974). Knowledge and Justification. Princeton, NJ: Princeton University Press.

Pollock, J. L. (1987). Defeasible reasoning. Cognitive Science, 11, 481-518.

Reznitskaya, A., Anderson, R. C., McNurlen, B., Nguyen-Jahiel, K., Archodidou, A., \& Kim, S. (2001). Influence of oral discussion on written argument. Discourse Processes, 32, 155-175.

Toulmin, S. (1958). The uses of argument. Cambridge, UK: Cambridge University Press.

van Eemeren, F. H., \& Grootendorst, R. (1984). Speech acts in argumentative discussions: A theoretical model for the analysis of discussions directed towards solving conflicts of opinion. Dordrecht, Netherlands: Floris Publications.

van Eemeren, F. H., \& Grootendorst, R. (1992). Argumentation, communication, and fallacies: A pragma-dialectical perspective. Hillsdale, NJ: Lawrence Erlbaum Associates. 
van Eemeren, F. H., \& Grootendorst, R. (2004). A systematic theory of argumentation. The pragmadialectical approach. Cambridge, UK: Cambridge University Press.

van Laar, J. A. (2014). Criticism in need of clarification. Argumentation, 28, 401-423.

Vygotsky, L. S. (1978). Mind and society: The development of higher mental processes. London, UK: Havard University Press.

Walton, D. (2005). How to evaluate argumentation using schemes, diagrams, critical questions and dialogues. Studies in Communication Sciences, Argumentation in Dialogic Interaction, Special Issue, 51-74.

Walton, D. (2006). Fundamentals of critical argumentation. New York, NY: Cambridge University Press.

Walton, D. (2007). Metadialogues for resolving burden of proof disputes. Argumentation, 21, 291-316.

Walton, D., \& Krabbe, E. (1995). Commitment in dialogue. Basic concepts of interpersonal reasoning. Albany, NY: State University of New York Press.

Walton, D., Reed, C., \& Macagno, F. (2008). Argumentation schemes. New York, NY: Cambridge University Press.

Zohar, A., \& Ben David, A. (2008). Explicit teaching of meta-strategic knowledge in authentic classroom situations. Metacognition and Learning, 3, 59-82.

Zohar, A. (2012). Explicit teaching of metastrategic knowledge: Definitions, students' learning, and teachers' professional development. In A. Zohar \& Y. J. Dori (Eds.), Metacognition in science education. Contemporary trends and issues in science education (pp. 197-223). Dordrecht, Netherlands: Springer. 